\title{
Embedded Teacher Training System Based on Integrated Teaching Mode
}

\author{
Di Miao ${ }^{1, a}$, Xiang Li ${ }^{1, b}$, Xiaoman Huang ${ }^{1, ~ c}$, Yinjian Zhong ${ }^{1, d}$ and \\ Mingming Sun ${ }^{1, e}$ \\ ${ }^{1}$ School of Electronic Engineering, Tianjin University of Technology and Education, \\ Tianjin 30000, China. \\ a09111042@bjtu.edu.cn, bcklx90@163.com, c16313633@qq.com, d1321302415@qq.com, \\ emmsun8808@163.com
}

\begin{abstract}
The existing embedded teaching and training mode has the problems of rigid teaching mode and single educational means. This paper studies an embedded teacher training system based on integrated project teaching, and constructs the organic combination of the three systems of the theory teaching system, the project case teaching system and the training project system, optimizes the application model of the embedded personnel training, and realizes the training program for the teachers in the teaching and teaching methods at the same time. The aim is to achieve the level of training teachers and achieve the goal of training applied talents.
\end{abstract}

Keywords: Integrated teaching, embedded, project teaching, practice.

\section{Introduction}

Embedded system is a new developing direction in recent years. It has a broad prospect of employment, which can be used in many industries, such as insurance industry, medical industry, financial industry, vehicle navigation, intelligent agriculture and so on. Because of this, market demand for embedded personnel is increasing, and wages are rising, especially for embedded engineers. According to statistics: the average salary of embedded engineers in China is nearly 13000 Yuan, of which $21.4 \%$ of salaries are between $20 \mathrm{k}-30 \mathrm{k}$. In the first tier cities, such as Beijing, Shanghai, Shenzhen and other places, the average salary of embedded engineers is as high as 16000 Yuan / month [1]. It can be seen that embedded engineers will be an indispensable part of the development of enterprises both now and in the future.

The curriculum of embedded vocational teachers is a course based on the combination of software development and the organic combination of hardware. However, the embedded teaching method of traditional classroom teaching and experimental model has the disadvantages of dictatorship, neglect of individuality and single means; the theory course is boring and boring [3], it is detached from practice, and the students' participation is low; the experiment course is [2] There are problems in experiment design, such as difficulty in design, large difference in [4], low participation in backward students, and difficulty in adjusting experimental arrangements. Therefore, this paper studies the embedded "integrated" curriculum architecture suitable for the training of embedded teachers, and describes the curriculum from the overview of the integrated teaching model, the goal of the course construction, the concrete realization method and the training of the teachers.

\section{Overview of the "Integrated" Teaching Model}

Because the course nature of the embedded course itself has a strong practical [5], this article adopts the integrated model of "theory teaching and experimental teaching" to improve the applicability of theory teaching to reduce its dull degree. Students can carry on the design and programming of the embedded system after the study of the theoretical knowledge. The curriculum characteristics of the combination of theory and practice can make up for the shortcomings of the traditional teaching methods. The following teaching methods are adopted in the concrete teaching reform: 


\subsection{Adjust the Content of Teaching}

The teaching content of the foundation of the embedded system is adjusted to solve several practical problems, so that the course content is closer to the reality and the students' ability to think and solve problems independently. Using real situation to arouse students' interest in learning, to satisfy students' thirst for knowledge and enterprising spirit of active exploration. If students are interested in what they have learned, students will be able to receive better and more efficient learning results.

\subsection{Over Turn the Class}

Take students as the main part and set up reasonable situations in the classroom. At the end of the project, we draw the successful experience of the situation teaching reform at home and abroad, let the students demonstrate and explain the design, and refine and sublimate the theoretical knowledge and effectively exercise the students' ability.

\section{The Goal of Classroom Construction}

The following construction targets have been set:

(1) Change the traditional way of teaching and learning and improve the acceptance of theoretical teaching it provides new teaching materials suitable for integrated teaching, and presents the basic principles, software platform, hardware Support and other theoretical knowledge of students' embedded development in the process of project promotion.

(2) Take the project as the core and improve students' ability to find and solve problems in practice eight projects are provided to solve practical problems, so that students can reasonably apply the knowledge they have learned in the process of realizing the basic requirements of the project. Use the real situation to arouse students' interest in learning and satisfy their thirst for knowledge and enterprising spirit of active exploration.

(3) Develop embedded skills competition to mobilize students' learning enthusiasm courses related skills competitions are held to encourage students to actively participate in various related activities. L .et students improve in the competition, cultivate students' comprehensive ability and infiltrate classroom teaching influence.

(4) Participate in relevant academic activities to improve the embedded business ability of teachers and students are selected to attend lectures or seminars on cutting-edge knowledge of embedded systems, so that students can have an opportunity to have in depth exchange and study, and promote the all-around development of students' abilities.

\section{Specific Implementation Methods}

Embedded classes have "C language program design", the single chip microcomputer system and application, such as eight of the actual project design, through the analysis of the source code and system design method, help students learn principles of microprocessor based on ARM kernel, embedded software technology and embedded Linux operating system the basic principle and method of embedded system and embedded system design ability. On the importance of embedded system course, practical characteristic sand detailed introduction of embedded system course design development board hardware circuit diagram and ISP (in system programming) technology based programming circuit diagram and the concrete steps of the Curriculum implementation process, including topic selection method, hardware circuit design and welding, software design and algorithm analysis, software simulation and debugging, the system programming and debugging running, and teacher's specific scoring method. The newly designed curriculum plan is applied to the embedded system curriculum teaching in the current year. The vivid and flexible teaching method is adopted to make appropriate adjustments according to the specific situation of curriculum implementation.

In the course implementation process, the Curriculum reform is constantly adjusted and reformed according to students' classroom feedback, so as to optimize the curriculum reform .Regularly issue 
survey questionnaires to understand students' learning tendency and learning experience at the current stage, to understand students' learning objectives and expectations of course objectives. In the process of interaction, we will continue to adjust all aspects of the course plan and make continuous improvement and modification. Understand the student's Suggestions for the course listen and act on them. A novel teaching link is designed to fully mobilize the enthusiasm of students and make this course more acceptable to students, So as to enhance the effect of the course and achieve the expected goal of reform. Examples of courseware are shown in figure 1, and students' works are shown in figure 2.

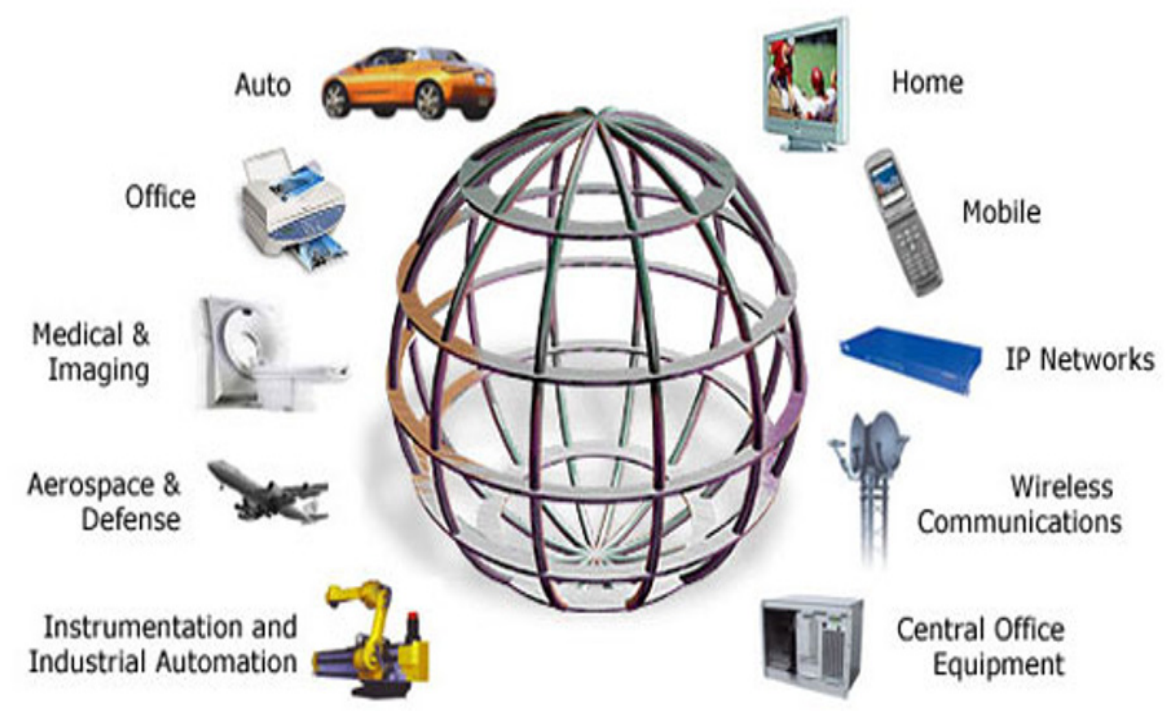

Figure 1. Courseware examples

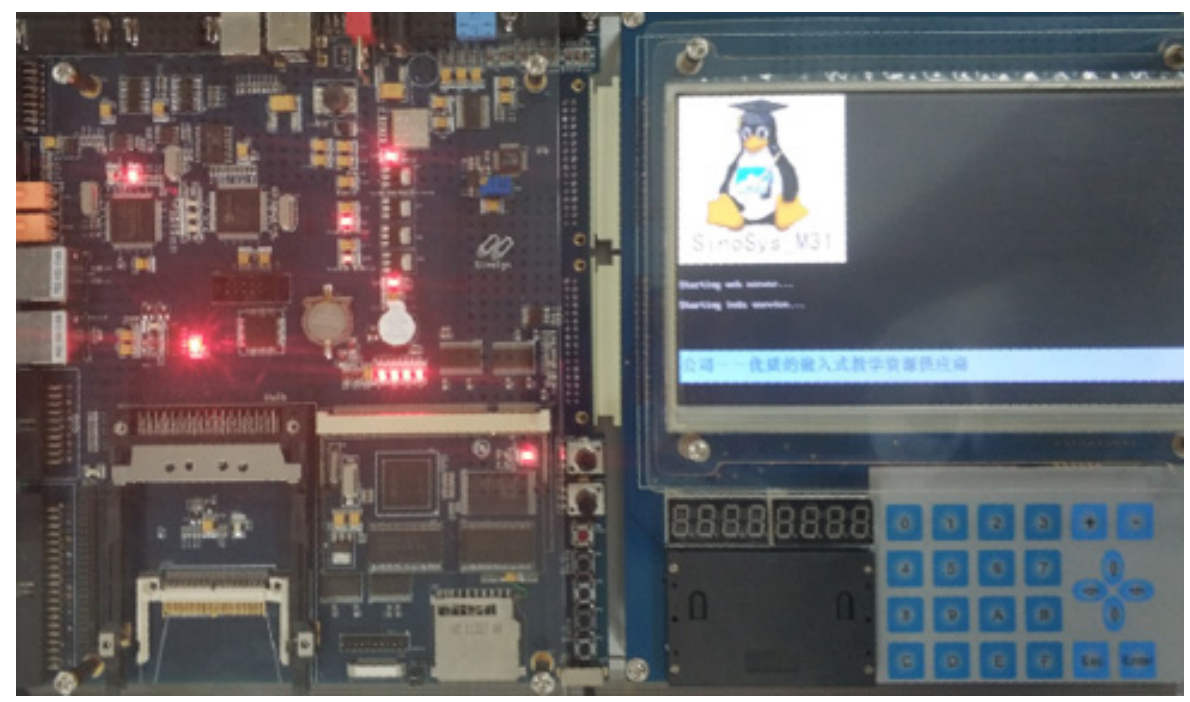

Figure 2. Student work

\section{Summary}

This paper studies an embedded teacher training system based on integrated project teaching, and constructs an organic combination of the theoretical teaching system, the project case teaching system and the training project system. The targeted teacher training is targeted the design of. For this reason, this paper studies the embedded "integrated" curriculum architecture for embedded vocational teacher training, which includes the following aspects: an overview of the integrated teaching model, curriculum construction goals, specific implementation methods, and vocational teacher training description. 
Optimize the application-based embedded talent training mode, realize the teaching and teaching method and teach the teacher training program to achieve the practical level of training teachers, and achieve the purpose of cultivating applied talents.

\section{Acknowledgements}

Support by Tianjin Natural Science Foundation (17KPHDSF00290, 16KPHDSF00050), Tianjin Science and Technology Project (17JCTPJC48300, 16ZXHLSF00200), Tianjin Education Commission Scientific Research Plan Project (JWK1606), Tianjin University of Technology and Education talent start-up project (KYQ01614), Tianjin Education Science "13th Five-Year Plan" Plan (VEYP5044), and University Student Innovation Training Program (201810066056).

\section{References}

[1]. Zhang P. Study on the Embedded Governance and Its Institutional Supply of Vocational Education [J]. Vocational \& Technical Education, 2016.

[2]. Xing X G. Research on the Innovation of Chinese Teaching in Higher Vocational Colleges from the Perspective of Vocational Education [J]. Journal of Hubei Correspondence University, 2017.

[3]. Tong W, Jiang T, Education S O, et al. Research on Construction of Professional Teaching Database in Higher Vocational Education[J]. China Higher Education Research, 2016.

[4]. Feng Y, Education D O, Polytechnic L. Analysis on the Current Situation and Problems of Higher Vocational Education in Mountain Area [J]. Journal of Hubei Correspondence University, 2016.

[5]. Kessler M. Areas of Learning: The Shift towards Work and Competence Orientation Within the School-based Vocational Education in the German Dual Apprenticeship System [J]. 2016.

[6]. Wolf S. International Technical and Vocational Education and Training (TVET) Transfer Project - Theoretical-Practical Experiences of Workplace Training with the Workforce in the Egyptian Construction Industry [M]// Vocational Education and Training in Times of Economic Crisis. Springer International Publishing, 2017. 